feeding and will improve the prospects of early hospital discharge. We are carrying out further work to determine the effects on long term quality of life in such patients, and our preliminary results have so far been encouraging. In addition, further work is required to determine the ideal timing at which to institute gastrostomy feeding after an acute dysphagic stroke.

Funding: None.

Conflict of interest: None.

1 Walton IN. Brain's diseases of the nervous system. 10th ed. Oxford: Oxford University Press, 1993.

2 Gordon C, Langton Hewer R, Wade DT. Dysphagia in acute stroke. BMF 1987;295:411-4.

3 Barer DH. Lower cranial nerve motor function in unilateral vascular lesions of the cerebral hemisphere. $B M \mp$ 1984;289:1622.

4 Veis SL, Logemann JA. Swallowing disorders in persons with cerebrovascular accident. Arch Phys Med Rehabil 1985;66:372-5.

5 Wolfsen H, Kozarek R. Percutaneous endoscopic gastrostomy. Ethical considerations. Gastroenterol Clin North Am 1993;2:259-71.

6 Ciocon JO, Silverstone FA, Graver M, Foley CJ. Tube feeding in elderly patients. Arch Intern Med 1988;148:429-33.

7 Wicks C, Gimson A, Vlavianos P, Lombard M, Panos M, Macmathuna P, et al. Assessment of the percutaneous endoscopic gastrostomy feeding tube as part of an integrated approach to enteral feeding. Gut 1992;33:613-6.

8 Rees RGP, Payne-James JJ, King C, Silk DBA. Spontaneous transpyloric passage and performance of fine bore polyurethane feeding tubes: a controlled clinical trial. Foumal of Parenteral and Enteral Nutrition 1988:12: 469-72.

9 Abernathy G, Heizer W, Holcombe B, Raasch R, Schlegel K, Hak L, et al. Efficacy of tube feeding in supplying energy requirements of hospitalised patients. Foumal of Parenteral and Enteral Nutrition 1989;13:387-91.

10 Ponsky JL, Gauderer MWL. Percutaneous endoscopic gastrostomy: a nonoperative technique for feeding gastrostomy. Gastrointest Endosc 1981;27: 9-11.

11 Jones M, Santanello SA, Falcone RE. Percutaneous endoscopic versus surgical gastrostomy. Foumal of Parenteral and Enteral Nutrition 1990;14:533-4.

12 Peters RA, Westaby D. Percutaneous endoscopic gastrostomy. Indications, timing and complications of the technique. Br f Int Care 1994;4:88-95.

13 Larson DE, Burton DD, Schroeder KW, DiMagno EP. Percutaneous endoscopic gastrostomy. Indications, success, complications, and mortality endoscopic gastrostomy. Indications, success, complications,
in 314 consecutive patients. Gastroenterology 1987;93:48-52.

14 Raha SK, Woodhouse K. The use of percutaneous endoscopic gastrostomy (PEG) in 161 consecutive elderly patients. Age Ageing 1994;23:162-3.

15 Mahoney FI, Barthel DW. Functional evaluation: the Barthel index. Md Med f 1965;14:61-5.

16 Grant J. Comparison of percutaneous endoscopic gastrostomy with Stamm gastrostomy. Ann Surg 1988;207:598-603.

17 Park RHR, Allison MC, Lang J, Spence E, Morris A J, Danesh BJZ, et al. Randomised comparison of percutaneous endoscopic gastrostomy and nasogastric tube feeding in patients with persisting neurological dysphagia. $B M Y$ 1992;304:1406-9.

18 A positive approach to nutrition as treatment. Kings Fund report on the role of enteral and parenteral feeding in hospital and at home. London: King's Fund Centre, 1992.

19 Stone SP, Whincup P. Standards for the hospital management of stroke patients. $\mathcal{F}$ Coll Physicians Lond 1994;28:52-8.

(Accepted 24 October 1995)

\title{
Prenatal and postnatal prevalence of Turner's syndrome: a registry study
}

\author{
Claus Højbjerg Gravholt, Svend Juul, Rune Weis Naeraa, Jan Hansen
}

\section{Medical Department M \\ (Endocrinology and \\ Diabetes), Aarhus \\ Kommunehospital, \\ University Hospital of \\ Aarhus, DK-8000 \\ Aarhus C, Denmark \\ Claus Højbjerg Gravholt, \\ research fellow}

\section{Department of}

Epidemiology and Social

Medicine, University of

Aarhus

Svend Juul, associate

professor

Paediatric Department A, Aarhus Kommunehospital, University Hospital of

Aarhus

Rune Weis Naeraa, registrar

\section{Danish Cytogenetic}

Central Register, Aarhus

Psychiatric Hospital,

University Hospital of

Aarhus

Jan Hansen, EDP

programmer

Correspondence to: -

Dr Gravholt.

\section{Abstract}

Objective-To study prevalence of Turner's syndrome in Denmark and to assess validity of prenatal diagnosis.

Design-Study of data on prenatal and postnatal Turner's syndrome in Danish Cytogenetic Central Register.

Subjects-All registered Turner's syndrome karyotypes (100 prenatal cases and 215 postnatal cases) during 1970-93.

Main outcome measures-Prevalence of Turner's syndrome karyotypes among prenatally tested fetuses and Turner's syndrome among liveborn infants.

Results-Among infant girls, prevalence of Turner's syndrome was 32/100000. Among female fetuses tested by amniocentesis, prevalence of Turner's syndrome karyotypes was $176 / 100000$ (relative risk of syndrome, 6.74 compared with prevalence among untested pregnancies). Among female fetuses tested by chorion villus sampling, prevalence of syndrome karyotypes was $392 / 100000$ (relative risk, 16.8). We excluded prenatal tests referred because of results of ultrasound scanning: among fetuses tested by amniocentesis revised relative risk was 5.68 , while revised relative risk among fetuses tested by chorion villus sampling was 13.3. For 29 fetuses with prenatal diagnosis of possible Turner's syndrome, pregnancy was allowed to continue and 24 children were live born. Thirteen of these children were karyotyped postnatally, and diagnosis of Turner's syndrome had to be revised for eight, seven being normal girls and one boy. This gives tentative predictive value of amniocentesis in diagnosing Turner's syndrome of between $21 \%$ and $67 \%$. There was no significant relation between mother's age and risk of Turner's syndrome.

Conclusions-Discrepancy between prenatal and postnatal prevalence of Turner's syndrome challenges specificity of prenatal examination in diagnosing Turner's syndrome.

\section{Introduction}

Turner's syndrome is a disorder of female patients that is typically associated with the absence of one sex chromosome $(45, \mathrm{X})$, although structural abnormality of one sex chromosome or mosaicism may also be responsible. The prevalence of Turner's syndrome at birth has been studied, so far, only in large scale chromosome surveys of children. In white populations it has been estimated to be $25-55$ per 100000 females $^{1-3}$ and in Japanese populations to be $70-210$ per $100000 .^{4}$ The high prevalence of 210 per 100000 was found in a small study of only 2400 females. It has recently been suggested that advanced maternal age may be a risk factor for giving birth to a child with Turner's syndrome, ${ }^{5}$ while other workers have found that maternal age is inversely related to the occurrence of monosomy $X(45, X)$ in offspring. ${ }^{6-8}$

All cytogenetic laboratories in Denmark report all prenatal and postnatal karyotype examinations to the Danish Cytogenetic Central Registry. The register is excellent for studying epidemiological aspects of Turner's syndrome. There has recently been a rise in the numbers of fetuses with prenatally diagnosed Turner's syndrome in Denmark. We used data from the Danish Cytogenetic Central Register to try to estimate whether this reflected a true rise in the prevalence of Turner's syndrome; if it was simply a reflection of the increased use of amniocentesis, chorion villus sampling, and ultrasonography; or if it was related to other factors.

\section{Subjects and methods}

In Denmark seven laboratories perform postnatal karyotyping, and four of these also perform prenatal karyotyping. All results are reported to the Danish Cytogenetic Central Register. The register includes information on maternal age, whether prenatal results were obtained by amniocentesis or chorion villus sampling, if amniocentesis or chorion villus sampling was preceded by ultrasonography (information about 
ultrasonography has been available since 1989), and the outcome of the pregnancy (induced abortion, spontaneous abortion, live birth). The register does not include information on the number of cells analysed. However, when a normal karyotype is encountered at least 10 cells are analysed, and when a Turner's karyotype is suspected at prenatal examination at least 50 cells, but normally 100 cells or more, from two different cultures are analysed. The register has issued an annual report since $1978 .^{9}$

In Denmark all pregnant women aged over 35 are given the opportunity of having a prenatal examination. For a pregnant woman aged under 35 to be offered a prenatal examination, there would have to be an indication: these include advanced age of father $(>50)$; previous child with chromosomal abnormality, mental retardation, or congenital abnormality; family history of chromosomal abnormality or mental retardation; habitual abortions; parental exposure to mutagens or teratogens; decreased concentration of serum $\alpha$ fetoprotein in maternal serum; abnormal findings at ultrasonography; parental anxiety; parents carrying a chromosome aberration; increased risk of monogenic inheritable diseases; increased risk of open defects (spina bifida, anencephaly, etc). Postnatal

Table 1-Distribution of all prenatal and postnatal Turner's syndrome karyotypes. Values are numbers of cases

\begin{tabular}{lcc}
\hline Karyotype & Prenatal & Postnatal* \\
\hline $45, X$ & 62 & 109 \\
$45, X / 46, X X$ & 22 & 29 \\
$45, X / 46, X, i(X q) ; 46, X, X,(X q) ; 45, X / 46, X, i(X q) / 47, X, i(X q), i(X q) ;$ etc & 6 & 27 \\
$45, X / 46, X$, ,del $(X) ; 46, X, d e(X)$ & 5 & 18 \\
$45, X / 46, X X 47, X X X ; 45, X / 47, X X X ; 45, X / 46, X X / 47, X X X / 48, X X X X$ & 3 & 7 \\
$45, X / 46, X, X(X)$ & 2 & 14 \\
$45, X / 46, X Y$ & & 6 \\
Others with $Y$ material & & 5 \\
\hline Total & 100 & 215 \\
\hline
\end{tabular}

*Though some of the prenatally diagnosed cases of Turner's syndrome came to term, they are not included in the postnatal group. karyotyping of infants is performed on the basis of clinical signs.

We studied the period 1970-93 as amniocentesis was introduced in Denmark in 1970 and looked for all possible Turner's syndrome karyotypes affecting the $\mathrm{X}$ chromosome. (We did not include karyotypes affecting the $\mathrm{Y}$ chromosome, since the karyotype 45,X/46,XY is known to result in an array of phenotypes such as phenotypic females with or without virilising features, Turner's syndrome, intersex with ambiguous genitalia, and phenotypic males with or without genital malformations. ${ }^{11}$ ) Our study was approved by the local ethics scientific committee and by the national registry authorities.

\section{STATISTICAL METHODS}

We used the binomial distribution to calculate confidence limits; the Mantel-Haenszel method to calculate relative risk stratifying by year, or the Pearson $\chi^{2}$ test when stratification was not feasible; logistic regression to test whether a change was taking place in the prevalence of Turner's syndrome diagnosed over the years; and the $\chi^{2}$ test for trend (MantelHaenszel test for linear association) to test for any maternal age effect. The statistics were done with SPSS for Windows, version 6.0.1 (SPSS, Chicago IL, USA).

\section{Results}

Table 1 shows all the Turner's syndrome karyotypes recorded in the cytogenetic register during 1970-93. There was a higher proportion of the 45,X karyotype in prenatal diagnoses compared with postnatal findings, but the difference was not significant $\left(\chi^{2}=3.51, \mathrm{df}=1\right.$, $P=0 \cdot 06)$. There were no differences between prenatal and postnatal diagnoses for the other groups of karyotypes.

Table 2 shows the number and prevalence of prenatal and postnatal diagnoses of Turner's syndrome. The overall proportion of liveborn infant girls with Turner's syndrome was 32 (95\% confidence interval 28 to 37) per 100000 . The overall proportion of liveborn infant girls with the syndrome after untested pregnancies was also 32 (27 to 36 ) per 100000 . The overall

Table 2-Prenatal and postnatal diagnosis of Turner's syndrome by year

\begin{tabular}{|c|c|c|c|c|c|c|c|c|}
\hline \multirow[b]{2}{*}{ Year } & \multirow[b]{2}{*}{$\begin{array}{c}\text { Prenatal } \\
\text { diagnosis (year } \\
\text { of diagnosis) }\end{array}$} & \multirow[b]{2}{*}{$\begin{array}{l}\text { Liveborn } \\
\text { infants with } \\
\text { syndrome } \\
\text { (year of birth) }\end{array}$} & \multicolumn{2}{|c|}{ Prenatal diagnosis in females } & \multirow[b]{2}{*}{$\begin{array}{l}\text { Postnatal } \\
\text { diagnosis among } \\
\text { untested girls } \\
\text { (year of birth) }\end{array}$} & \multicolumn{3}{|c|}{ Prevalence per 100000} \\
\hline & & & Amniocentesis & $\begin{array}{l}\text { Chorion } \\
\text { villus } \\
\text { sampling }\end{array}$ & & Amniocentesis & $\begin{array}{l}\text { Chorion } \\
\text { villus } \\
\text { sampling }\end{array}$ & $\begin{array}{l}\text { Untested } \\
\text { liveborn } \\
\text { girls }\end{array}$ \\
\hline 1970 & 0 & 12 & $0 / 3$ & & $12 / 34417$ & 0 & & 35 \\
\hline 1971 & 0 & 15 & $0 / 10$ & & $15 / 36394$ & 0 & & 41 \\
\hline 1972 & 0 & 16 & $0 / 31$ & & $16 / 36782$ & 0 & & 43 \\
\hline 1973 & 0 & 16 & $0 / 52$ & & $16 / 34944$ & 0 & & 46 \\
\hline 1974 & 0 & 17 & 0/169 & & $17 / 34602$ & 0 & & 49 \\
\hline 1975 & 0 & 14 & $0 / 312$ & & $14 / 34948$ & 0 & & 40 \\
\hline 1976 & 0 & 7 & $0 / 380$ & & $7 / 31153$ & 0 & & 22 \\
\hline 1977 & 0 & 5 & $0 / 606$ & & $5 / 29449$ & 0 & & 17 \\
\hline 1978 & 2 & 14 & $2 / 973$ & & $14 / 29190$ & 206 & & 48 \\
\hline 1979 & 3 & 10 & $3 / 1402$ & & $10 / 27510$ & 214 & & 36 \\
\hline 1980 & 4 & 10 & $4 / 1759$ & & $10 / 26186$ & 227 & & 38 \\
\hline 1981 & 6 & 10 & $6 / 2025$ & & $9 / 23953$ & 296 & & 38 \\
\hline 1982 & 4 & 4 & $4 / 2366$ & & $4 / 23233$ & 169 & & 17 \\
\hline 1983 & 5 & 7 & $5 / 2826$ & $0 / 4$ & $6 / 21996$ & 177 & 0 & 27 \\
\hline 1984 & 2 & 6 & $2 / 2736$ & $0 / 64$ & $6 / 22430$ & 73 & 0 & 27 \\
\hline 1985 & 2 & 7 & $1 / 2634$ & $1 / 110$ & $6 / 23542$ & 38 & 909 & 25 \\
\hline 1986 & 5 & 5 & $3 / 2886$ & $2 / 300$ & $3 / 23697$ & 104 & 667 & 13 \\
\hline 1987 & 4 & 7 & $2 / 2735$ & $2 / 510$ & $6 / 23901$ & 73 & 392 & 25 \\
\hline 1988 & 6 & 9 & $5 / 3001$ & $1 / 604$ & $6 / 24921$ & 167 & 166 & 24 \\
\hline 1989 & 8 & 10 & $7 / 2775$ & $1 / 685$ & $7 / 26424$ & 252 & 146 & 26 \\
\hline 1990 & 6 & 8 & $4 / 2678$ & $2 / 924$ & $6 / 27217$ & 149 & 216 & 22 \\
\hline 1991 & 11 & 10 & $4 / 2612$ & $7 / 1264$ & $8 / 27489$ & 153 & 554 & 29 \\
\hline 1992 & 20 & 13 & $12 / 2770$ & $8 / 1352$ & $6 / 28812$ & 433 & 592 & 21 \\
\hline 1993 & 12 & 7 & $7 / 2616$ & $5 / 1582$ & $6 / 28485$ & 268 & 316 & 21 \\
\hline Total & 100 & 239 & $71 / 40357$ & $29 / 7399$ & $215 / 681475$ & 176 & 392 & 32 \\
\hline
\end{tabular}


proportion of cases of prenatally and postnatally diagnosed Turner's syndrome combined was 43 (39 to 48) per 100000 females. When diagnoses of Turner's syndrome were pooled regardless of ascertainment there was a significant rise in the prevalence over the years (logistic regression: yearly change in odds 1.016 $(1.0004$ to 1.031$), P=0.045)$.

\section{POSTNATAL DIAGNOSES}

About $46 \%$ of all postnatal diagnoses of Turner's syndrome were made within the first five years of life, $60 \%$ were made within the first 10 years, and $90 \%$ were made within the first 15 years. Turner's syndrome was diagnosed significantly later among children who were born during 1970-80 than among those who were born in 1981-93 (figure): for those born in $1970-80,28 \%$ (38/ 136) of all postnatal diagnoses of Turner's syndrome were found during the first five years of life, while, for those born in 1981-93, 76\% (60/79) of diagnoses were found during the first five years.

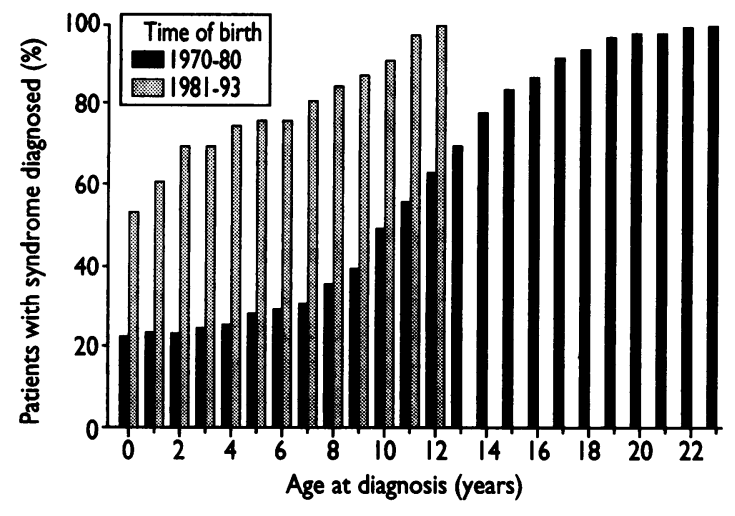

The prevalence of postnatally diagnosed Turner's syndrome in each birth cohort declined over the years (logistic regression: yearly change in odds 0.969 (95\% confidence interval 0.950 to 0.987 ), $P=0.001$ ). These comparisons are, however, biased, since some cases of Turner's syndrome in the recent birth cohorts would not have yet been diagnosed.

PRENATAL DIAGNOSIS

Diagnosis by amniocentesis

Among female fetuses tested by amniocentesis, the prevalence of Turner's syndrome karyotypes was $\mathbf{1 7 6}$ (134 to 215) per 100000 . The relative risk of the diagnosis, compared with the prevalence of postnatal diagnoses after untested pregnancies, was $6 \cdot 74(5 \cdot 21$ to 8.73) (Mantel-Haenszel method: $\chi^{2}=211$, $\mathrm{df}=1$, $P<0.0001)$. The proportion of amniocentesis tests with positive results increased non-significantly over the years (logistic regression: yearly change in odds

Table 3-Prevalence of prenatal diagnosis of Turner's syndrome by method of testing and by referral after ultrasonography. Values are numbers of subjects unless stated otherwise

\begin{tabular}{|c|c|c|c|c|c|}
\hline \multirow[b]{2}{*}{ Test used } & \multicolumn{2}{|c|}{$\begin{array}{l}\text { Test for Turner's } \\
\text { syndrome }\end{array}$} & \multirow[b]{2}{*}{ Total } & \multirow{2}{*}{$\begin{array}{l}\text { Prevalence } \\
\text { per } 100000\end{array}$} & \multirow{2}{*}{$\begin{array}{c}\text { Relative risk (95\% } \\
\text { confidence interval)" }\end{array}$} \\
\hline & Positive & Negative & & & \\
\hline $\begin{array}{l}\text { Amniocentesis: } \\
\text { Without ultrasonography } \\
\text { Preceded by ultrasonography } \\
\text { Chorion villus sampling: } \\
\text { Without ultrasonography } \\
\text { Preceded by ultrasonography } \\
\text { None }\end{array}$ & $\begin{array}{r}71 \\
60 \\
11 \\
29 \\
23 \\
6 \\
215\end{array}$ & $\begin{array}{r}40286 \\
40169 \\
117 \\
7370 \\
7350 \\
20 \\
681460\end{array}$ & $\begin{array}{r}40357 \\
40230 \\
128 \\
7399 \\
7373 \\
26 \\
681675\end{array}$ & $\begin{array}{r}176 \\
149 \\
8594 \\
392 \\
312 \\
23077 \\
32\end{array}$ & $\begin{array}{c}6.74(5.21 \text { to } 8.73) \\
5.68(4.30 \text { to } 7.50) \\
276(144 \text { to } 467) \\
16.8(11.9 \text { to } 23.7) \\
13.3(9.06 \text { to } 19.5) \\
741(315 \text { to } 1347) \\
1.00\end{array}$ \\
\hline Total & 315 & 728993 & 729431 & 43 & \\
\hline
\end{tabular}

*Compared with no test used.
Table 4-Fate of fetuses with prenatal diagnosis of Turner's syndrome. Values are numbers of subjects

\begin{tabular}{lcc}
\hline & \multicolumn{2}{c}{ Method of testing } \\
\cline { 2 - 3 } & Amniocentesis & $\begin{array}{c}\text { Chorion } \\
\text { villus sampling }\end{array}$ \\
\hline Diagnosed & 71 & 29 \\
Legally aborted & 47 & 24 \\
Continued pregnancy: & 24 & 5 \\
Live born & 22 & 2 \\
Spontaneous abortion & 2 & 3 \\
\hline
\end{tabular}

$1.050(0.996$ to $1 \cdot 107), P=0.07)$. Amniocentesis was on average performed in the 16 th week of pregnancy.

\section{Diagnosis by chorion villus sampling}

Among female fetuses examined by chorion villus sampling, the prevalence of Turner's syndrome karyotypes was 392 (252 to 538 ) per 100000 . The relative risk of the diagnosis, compared with the prevalence of postnatal diagnoses after untested pregnancies, was $16.8(11.9$ to 23.7$)$ (Mantel-Haenszel method: $\left.\chi^{2}=258, \mathrm{df}=1, \mathrm{P}<0.0001\right)$. There was no change in the proportion of tests with positive results over the years. Chorion villus sampling was on average performed in the 11 th week of pregnancy.

\section{Adjustment for ultrasonography}

Since findings at ultrasonography can raise suspicion of Turner's syndrome, we made a revised calculation excluding women referred to prenatal karyotyping because of ultrasonographic findings. Prenatal examinations preceded by ultrasonography have been recorded at the Danish register since 1989. A total of 154 women carrying female fetuses were referred for amniocentesis or chorion villus sampling, and 17 of these fetuses had a Turner's syndrome karyotype.

After exclusion of these cases, the revised relative risk among amniocentesed compared with untested pregnancies was 5.68 (4.30 to 7.50) (Mantel-Haenszel method: $\left.\chi^{2}=150, \mathrm{df}=1, \mathrm{P}<0.0001\right)$. The increase over the years in the proportion of amniocentesis tests with positive results vanished when pregnancies referred due to ultrasonography were excluded (logistic regression: yearly change in odds $1.011(0.957$ to 1.068), $P=0 \cdot 70)$. The revised relative risk among pregnancies tested with chorion villus sampling was $13.3(9 \cdot 1$ to $19 \cdot 5)$ (Mantel-Haenszel method: $\chi^{2}=175$, $\mathrm{df}=1, \mathrm{P}<0.0001)$. Table 3 summarises these results.

\section{Fate of fetuses with diagnosis of Turner's syndrome}

Table 4 shows the fate of fetuses that had Turner's syndrome diagnosed prenatally. About $75 \%$ of all fetuses with the syndrome diagnosed are terminated legally in Denmark, with the proportion declining during recent years. During 1978-85, 86\% (24 of 28) of such fetuses were aborted, while $72 \%$ (51 of 72 ) were aborted during 1986-93.

For 29 fetuses with a possible prenatal diagnosis of Turner's syndrome, the parents chose to let the pregnancy continue, and 24 were live born. Table 4 shows the prenatal and postnatal status for these children. Of the 24 pregnancies that were allowed to continue after a positive amniocentesis test, $22(92 \%$ $(73 \%$ to $99 \%)$ ) successfully came to term and no deaths were recorded during the first year after birth. Of the five pregnancies that were allowed to continue after a positive result from chorion villus sampling, two survived to term.

Among the 24 liveborn infants, six had a prenatal 45,X karyotype while 18 had a mosaic Turner's syndrome karyotype (table 5). Thirteen of the liveborn children were karyotyped postnatally, and the diag- 
Table 5-Prenatal and postnatal karyotypes of 24 liveborn infants that had prenatal diagnosis of Turner's syndrome

\begin{tabular}{|c|c|c|c|}
\hline \multicolumn{2}{|c|}{ Prenatal examination } & \multicolumn{2}{|c|}{ Postnatal examination } \\
\hline Karyotype & No of subjects & Karyotype & No of subjects \\
\hline $45, X$ & 6 & Not examined* & 5 \\
\hline \multirow{4}{*}{$45, X / 46, X X$} & 15 & Not examined* & 5 \\
\hline & & $45, X / 46, X X$ & 3 \\
\hline & & $46, X X$ & 6 \\
\hline & & $45, X$ & 1 \\
\hline $45, X / 47, X X X$ & 1 & $45, X / 47, X X X$ & 1 \\
\hline $46, X X / 46, X$, del $(X)$ (pterq24) & 1 & $46, x \times$ & 1 \\
\hline $46, X X / 46, X, i(X q)$ & 1 & Not examined* & 1 \\
\hline \multirow[t]{4}{*}{ Turner's syndrome } & 24 & Not examined* & 11 \\
\hline & & Turner's syndrome & 5 \\
\hline & & Male $(45, X / 46, X$,idic $(Y))$ & 1 \\
\hline & & Normal female $(46, X X)$ & 7 \\
\hline
\end{tabular}

*Legally registered as female, but nothing known of phenotype or genotype.

tMale.

Table 6-Prevalence of detection of Turner's syndrome karyotypes at prenatal testing by age of mother. Values are numbers of subjects

\begin{tabular}{|c|c|c|c|}
\hline \multirow[b]{2}{*}{ Maternal age (years) } & \multicolumn{2}{|c|}{ Method of testing } & \multirow[b]{2}{*}{ Total } \\
\hline & Amniocentesis & Chorion villus sampling & \\
\hline $\begin{array}{l}\text { S24: } \\
\text { Prevalence* } \\
\text { 25-29: } \\
\text { Prevalence* } \\
\text { 30-34: } \\
\text { Prevalence* } \\
\text { 35-39: } \\
\text { Prevalence* } \\
\geqslant 40: \\
\text { Prevalence* } \\
\chi^{2} \text { Test for trend }(d f=1)\end{array}$ & $\begin{array}{c}7 / 3473 \\
202(81 \text { to } 415) \\
16 / 7076 \\
226(129 \text { to } 367) \\
17 / 9388 \\
181(106 \text { to } 290) \\
26 / 17822 \\
146(95 \text { to } 214) \\
5 / 2598 \\
192(63 \text { to } 449) \\
1.17(P=0.28)\end{array}$ & $\begin{array}{c}2 / 451 \\
443(54 \text { to } 1593) \\
7 / 1222 \\
573(231 \text { to } 1177) \\
5 / 1710 \\
292(95 \text { to } 681) \\
14 / 3359 \\
417(228 \text { to } 698) \\
1 / 657 \\
152(4 \text { to } 845) \\
0.78(P=0.38)\end{array}$ & $\begin{array}{c}9 / 3924 \\
229(105 \text { to } 435) \\
23 / 8298 \\
277(176 \text { to } 416) \\
22 / 11098 \\
198(124 \text { to } 300) \\
40 / 21181 \\
189(135 \text { to } 257) \\
6 / 3255 \\
184(68 \text { to } 401) \\
1.50(P=0.22)\end{array}$ \\
\hline $\begin{array}{l}\text { Total: } \\
\text { Prevalence* }\end{array}$ & $\begin{array}{c}71 / 40357 \\
176(137 \text { to } 219)\end{array}$ & $\begin{array}{c}29 / 7399 \\
392 \text { (263 to } 562)\end{array}$ & $\begin{array}{c}100 / 47856 \\
209(170 \text { to } 254)\end{array}$ \\
\hline
\end{tabular}

*With $95 \%$ confidence interval.

nosis of Turner's syndrome was revised for eight $(62 \%(32 \%$ to $86 \%))$ : seven had normal female karyotypes $(45, \mathrm{X} / 46, \mathrm{XX}$ revised to $46, \mathrm{XX}$ for six children; $46, \mathrm{XX} / 46, \mathrm{X}, \operatorname{del}(\mathrm{X})$ revised to $46, \mathrm{XX}$ for one) and one was male $(45, \mathrm{X}$ revised to $45, \mathrm{X} /$ $46, X$, idic $(Y))$. Furthermore, one Turner's syndrome karyotype was revised at postnatal examination $(45, \mathrm{X} /$ $46, \mathrm{XX}$ revised to $45, \mathrm{X})$. Among the other 11 children, we know that they were all legally females, but no further information was obtained about their phenotype. The probability of a fetus with a mosaic karyotype for Turner's syndrome surviving to term was significantly higher than that of a fetus with $45, \mathrm{X}$ karyotypes surviving $\left(\chi^{2}=18.4, \mathrm{df}=1, \mathrm{P}<0.0001\right)$.

Table 6 shows the prevalence of Turner's syndrome karyotypes at prenatal examinations by the age of the mother. There was no relation between the age of the mother and overall risk of Turner's syndrome. There was also no relation between the age of the mother and the 45,X karyotype. Excluding cases referred after ultrasonography did not change this (data and results not shown).

\section{Discussion}

DANISH CYTOGENETIC CENTRAL REGISTER

This register represents a unique opportunity for studying abnormal karyotypes, because all prenatal and postnatal examinations performed in Denmark are recorded here. The register can be considered complete, though administrative errors can never be excluded. The data we have extracted from the register cannot be thought of as representative of the Danish population of pregnant women, as most prenatal examinations are carried out on older women. This is not, however, a source of bias, as maternal age apparently is not a risk factor for giving birth to a female infant with Turner's syndrome, though conflicting results have been presented over the years. One study found no maternal age effect among a group of 288 girls with the 45,X karyotype of Turner's syndrome. ${ }^{6}$ Recently, another study showed a positive maternal age effect in a group of 772 girls with Turner's syndrome (all karyotypes pooled together). ${ }^{5}$ Our results show that there is no relation between maternal age and risk of Turner's syndrome (both overall and for the $45, \mathrm{X}$ karyotype only) at prenatal diagnosis.

Studies on spontaneous abortions, on the contrary, have shown that young maternal age is associated with aborting Turner's syndrome $(45, \mathrm{X})$ fetuses more frequently. ${ }^{78}$ It remains to be seen whether this finding can be extrapolated to the population with postnatally diagnosed Turner's syndrome, and we are currently investigating this. We had no information on paternal age.

The prenatal and postnatal groups were not completely comparable, as postnatal diagnosis is mainly based on clinical suspicion while prenatal diagnosis is mainly based on the age of the mother. This will of course, presuming that the postnatal diagnosis of Turner's syndrome is not complete, tend to underestimate the postnatal prevalence of Turner's syndrome. It is important to note that the information in the register is about karyotypes and not phenotypes. A Turner's syndrome karyotype might not necessarily result in a Turner's syndrome phenotype.

PRENATAL AND POSTNATAL PREVALENCE OF TURNER'S SYNDROME

We found that Turner's syndrome in Denmark was diagnosed prenatally at a rate that was much higher than the observed postnatal rate. The result was highly significant for both amniocentesis and chorion villus sampling, and when cases referred after ultrasonography were excluded. The rate of spontaneous abortion in the first trimester is estimated to be $99 \%$, but this high rate of abortion can only partially explain our findings. ${ }^{212}$ The fact that $91 \%$ of all fetuses with the syndrome detected by amniocentesis (and $40 \%$ of those detected by chorion villus sampling) survived until term when the pregnancy was not terminated suggests that other factors may play a role and that most fetuses with Turner's syndrome detected by amniocentesis are viable.

Hook and Warburton presented data from the New York State Chromosome Registry, where, for every 100000 female fetuses tested by amniocentesis, about 85 (95\% confidence interval 54 to 127$)$ cases of Turner's syndrome were detected. We found 176 (134 to 215 ) cases of Turner's syndrome for every 100000 amniocenteses and 392 (252 to 538) cases for every 100000 chorion villus samples, which are significantly higher figures. Hook and Warburton estimated the postnatal prevalence of Turner's syndrome to be $22 \cdot 2$ per 100000 females without intervention; they explained the difference in prevalence by an expected survival of the fetuses with Turner's syndrome $(45, \mathrm{X})$ of only $31 \%$ after an amniocentesis had been performed, based on the well known high lethality of especially the $45, \mathrm{X}$ karyotype, peaking according to their data at week $13 .{ }^{13}$ This is contrary to our finding that $92 \%$ of all fetuses with Turner's syndrome detected by amniocentesis, and $75 \%(35 \%$ to $97 \%)$ of fetuses with the $45, \mathrm{X}$ karyotype, survived to term if the 
pregnancy was not terminated. Some researchers have claimed that a degree of mosaicism must be present, at least in very early life, for survival in utero and that pure $45, \mathrm{X}$, as such, does not exist. ${ }^{14}$ In our study amniocentesis was performed on average in the 16th week of pregnancy, which is after the period of high intrauterine lethality during the first trimester. The high viability of fetuses with prenatally diagnosed Turner's syndrome, especially after amniocentesis, might be biased by the older age of the women undergoing prenatal examination compared with the rest of the pregnant population and might not be applicable to younger age groups.

The higher number of diagnoses of Turner's syndrome with amniocentesis cannot be explained by the increased use of ultrasonography. Ultrasonography seemed to be a rather good method of identifying some fetuses with Turner's syndrome (table 3), but only few cases of Turner's syndrome were found as a result of suspicious ultrasonographic findings.

The prevalence of Turner's syndrome has never been established, but cytogenetic studies have given estimates ranging from 25 to 210 per 100000 females, ${ }^{1-4}$ and most researchers seem to agree on a hypothetical proportion of 50 per 100000 girls in white populations. If the true proportion of Turner's syndrome is $\mathbf{5 0}$ per $\mathbf{1 0 0 0 0 0}$ females, then not all females with Turner's syndrome were postnatally diagnosed in the period 1970-93 (relative risk 0.65). When adding the prenatally diagnosed Turner's syndrome, we find a relative risk of $0.86(0.77$ to 0.96$)$, still a little lower than the expected proportion of 50 per 100000 , keeping in mind that the prenatal figure was contaminated by a number of karyotypically normal girls and boys.

The prevalence of cases of Turner's syndrome not found prenatally but diagnosed postnatally seemed to be decreasing in recent birth cohorts (logistic regression: yearly change in odds $0.969(0.950$ to 0.987$)$, $\mathrm{P}=0.001)$. This finding can partially be explained by ascertainment bias: not all liveborn infants with Turner's syndrome from recent cohorts have yet been diagnosed. It must also be noted that some cases found prenatally and subsequently aborted tend to lower the postnatal prevalence, though never more than $15 \%$ of pregnant women with female fetuses underwent prenatal examination each year. How to explain, then, that the total prevalence of diagnoses of Turner's syndrome (prenatal and postnatal) was increasing (logistic regression: yearly change in odds 1.016 $(1.0004$ to 1.031$), P=0.045)$ in spite of the aforementioned bias? We conclude that this increase was either a genuine reflection of a real increase or a biased result. Recently, several reports have indicated that sperm quality might be deteriorating. ${ }^{1516}$ Furthermore, a significant positive correlation between structural abnormalities in sperm karyotypes and age has been demonstrated. ${ }^{17}$ As the $X$ in 45, $X$ Turner's syndrome is of maternal origin in $85 \%$ of cases, ${ }^{18-24}$ indicating an error in the paternal sperm, it is tempting to speculate that this might be the basis for the apparent rise in the prenatally detected Turner's syndrome. On the other hand, the result might be biased by two mechanisms. One is that increased awareness among clinicians and the introduction of prenatal examinations increase the likelihood of a child or fetus with Turner's syndrome to be detected. The other is that the specificity of prenatal examinations is less than perfect, leading to false positive diagnoses.

SPECIFICITY OF PRENATAL TECHNIQUES IN DIAGNOSIS OF TURNER'S SYNDROME

The finding of a much higher prevalence of Turner's syndrome at prenatal karyotyping than postnatally raises doubts about the specificity of prenatal exami- nations for Turner's syndrome. We have tried to estimate the predictive value of a positive prenatal Turner's syndrome karyotype by comparing the prenatal and postnatal prevalences of Turner's syndrome, correcting for the risk of spontaneous abortion after the time of prenatal examination.

We found a spontaneous abortion rate after amniocentesis of $8 \%$ ( $1 \%$ to $27 \%$ ). If the rate of spontaneous abortions after amniocentesis is $30 \%$, a prevalence of 176 fetuses with Turner's syndrome karyotypes per 100000 at the time of amniocentesis corresponds to a prevalence at birth of 123 liveborn infants with Turner's syndrome per 100000 females. If the true prevalence at birth (without intervention) is $\mathbf{5 0}$ infants with Turner's syndrome per 100000 females the false positive rate is 73 per 100000 tests, yielding a specificity of 0.9993 . Because of the rarity of Turner's syndrome, this apparently satisfactory specificity corresponds to a predictive value of $41 \%$. If the true prevalence at birth is higher or lower than 50 per 100000 females the estimates of the specificity and the predictive value change accordingly.

\section{REVISION OF KARYOTYPES: FALSE POSITIVE CASES}

Another way of estimating the predictive value of the prenatal examination techniques is by studying the prenatal and postnatal karyotypes of the 24 liveborn children diagnosed prenatally. Table 5 shows that an appreciable number of prenatal karyotypes were revised after birth. Six newborn infants with the prenatal karyotype $45, \mathrm{X} / 46, \mathrm{XX}$ turned out to be girls with the normal female karyotype $46, \mathrm{XX}$, and one infant with the prenatal karyotype 46,XX/46,X, $\operatorname{del}(\mathrm{X})$ (pterq24) was also normal $(46, \mathrm{XX})$. Amniocytes are a mixture of ectodermal and endodermal cells, while postnatal karyotyping is performed on leucocytes; thus continued mosaicism-for example, in the skin or other parts of ectodermal and endodermal tissues-cannot theoretically be ruled out: It is of course important to stress that, from the registry data, we are not able to say anything of the relative distributions of the different cell lines in mosaic cases. We have previously shown that the percentage of mosaicism can change dramatically over time when examined postnatally, perhaps suggesting that similar changes can take place during fetal development. ${ }^{25}$

One fetus with a prenatal diagnosis of $45, \mathrm{X}$ turned out to be a male with the karyotype $45, \mathrm{X} / 46, \mathrm{X}, \operatorname{idic}(\mathrm{Y})$, while in another case a prenatal diagnosis of $45, \mathrm{X} /$ $46, \mathrm{XX}$ was revised postnatally to $45, \mathrm{X}$. Such problems of specificity have been reported only sporadically..$^{27}$ Although placental mosaicism is a well recognised problem in the use of chorion villus sampling ${ }^{28-32}$ this cannot explain the findings concerning amniocentesis. These data question the specificity of amniocentesis in the prenatal diagnosis of Turner's syndrome, and especially the predictive value of mosaicism at prenatal examination.

We found that, of the 24 fetuses with a prenatal diagnosis of Turner's syndrome that survived to term, five definitely had the syndrome, yielding a predictive value of $21 \%$. If the 11 girls that did not get karyotyped after birth are assumed to have had Turner's syndrome, the predictive value was $67 \%$. The mosaic karyotypes are particularly responsible for the low predictive value. If the $45, \mathrm{X}$ cases are discounted, the predictive value of Turner's syndrome mosaicism was $28 \%-61 \%$. It can be concluded that the predictive value of prenatal testing was between $21 \%$ and $67 \%$ in this population. It should be noted that possible Turner's syndrome karyotypes affecting the $\mathrm{Y}$ chromosome were not included in this study.

We tried to estimate the predictive value of a positive test in two different ways from the data available. Both ways led to similar estimates. The implication of this is 


\section{Key Messages}

- There has recently been a rise in the numbers of fetuses with prenatally diagnosed Turner's syndrome in Denmark

- We used data from the Danish Cytogenetic Central Register to try to estimate whether this reflected a true rise in the prevalence of Turner's syndrome

- Karyotypes of Turner's syndrome were diagnosed prenatally at a much higher rate than the observed postnatal rate of the syndrome

- Of 24 children who were live born after prenatal diagnosis of possible Turner's syndrome, 13 were karyotyped postnatally and diagnosis of Turner's syndrome had to be revised for eight, seven being normal girls and one a boy.

- Discrepancy between prenatal and postnatal prevalence of Turner's syndrome challenges specificity of prenatal examination in diagnosing Turner's syndrome

that one may assume that perfectly healthy fetuses could have been legally aborted over the years because of false positive prenatal diagnoses of Turner's syndrome.

\section{CONCLUSION}

Our study challenges the predictive value and the specificity of prenatal examination techniques (especially amniocentesis) in the diagnosis of Turner's syndrome. In Denmark geneticists recommend that aborted fetuses should be karyotyped, but unfortunately this does not always happen. Future research on this area should focus on every fetus with a prenatally diagnosed Turner's syndrome karyotype. Of particular interest would be the distribution of cells in cases of mosaic karyotypes, results from karyotyping of aborted fetuses, and karyotyping of infants with the syndrome who have not yet been examined postnatally.

Funding: CHG is supported with a research fellowship by the University of Aarhus.

Conflict of interest: None.

1 Jacobs PA, Melville M, Ratcliffe S, Keay AJ, Syme J. A cytogenetic survey of 11,680 newborn infants. Ann Hum Genet 1974;37:359-76.

2 Hook EB, Warburton D. The distribution of chromosomal genotype associated with Turner's syndrome: livebirth prevalence rates and evidence for diminished fetal mortality and severity in genotypes associated with structural X abnormalities or mosaicism. Hum Genet 1983;64:24-7.

3 Nielsen J, Wohlert M. Chromosome abnormalities found among 34,910 newborn children: results from a 13-year incidence study in Arhus, Denmark. Hum Genet 1991;87:81-3.

4 Imaizumi K, Kuroki Y. Prevalence of Turner syndrome in Japan. In: Hibi I,
Takano K, eds. Basic and clinical approach to Turner syndrome. Amsterdam: Excerpta Medica, 1993:3-6.

5 Bernasconi S, Larizza D, Benso L, Volta C, Vannelli S, Milani S, et at Turner's. syndrome in Italy: familial characteristics, neonatal data, standards for birth weight and for height and weight from infancy to standards for birch weight and for heigt

6 Carothers AD, Frackiewicz A, De Mey R, Collyer S, Polani PE, Osztovics M, et al. A collaborative study of the aetiology of Turner syndrome. Ann Hum Genet 1980;43:355-68.

7 Kajii T, Ohama K. Inverse maternal age effect in monosomy X. Hum Genet 1979;51:147-51.

8 Warburton D, Kline J, Stein Z, Susser M. Monosomy X: a chromosomal anomaly associated with young maternal age. Lancet $1980 ; \mathrm{i}: 167-9$.

9 Mikkelsen M, Philip J, Lundsteen C, Therkelsen AJ, Petersen GB, Hansen J. Proenatale undersdgelser $i$ Danmark 1992. Risskov: Denmark, 1992:1-56.

10 Wheeler M, Peakman D, Robinson A, Henry G. 45,X/46,XY mosaicism: contrast of prenatal and postnatal diagnosis. Am $\mathcal{F}$ Med Genet 1988;29:56571.

11 Chang HJ, Clark RD, Bachman $\mathrm{H}$. The phenotype of $45, \mathrm{X} / 46, \mathrm{XY}$ mosaicism: an analysis of 92 prenatally diagnosed cases. Am $\mathcal{F}$ Hum Genet 1990;46:15667.

12 Lippe B. Turner syndrome. Endocrinol Metab Clin North Am 1991;20:121-52.

13 Hook EB, Topol BB, Cross PK. The natural history of cytogenetically abnormal fetuses detected at midtrimester amniocentesis which are no terminated electively: new data and estimates of the excess and relative risk of late fetal death associated with $47,+21$ and some other abnormal karyotypes. Am $\mathcal{A}$ Hum Genet 1989;45:855-61.

14 Held KR, Kerber S, Kaminsky E, Singh S, Goetz P, Seemanova E, et al. Mosaicism in 45,X Turner syndrome: does survival in early pregnancy depend on the presence of two sex chromosomes? Hum Genet 1992;88:28894.

15 Carlsen E, Giwercman A, Keiding N, Skakkebaek NE. Evidence for decreasing quality of semen during past 50 years. $B M F$ 1992;305:609-13.

16 Keiding N, Giwercman A, Carlsen E, Skakkebaek NE. Falling sperm quality. BMF 1994;309:131.

17 Martin RH, Rademaker AW. The effect of age on the frequency of sperm chromosomal abnormalities in normal men. Am $\mathcal{F}$ Hum Genet 1987;41:484

18 Hassold T, Benham F, Leppert M. Cytogenetic and molecular analysis of sexchromosome monosomy. Am $\mathcal{F}$ Hum Genet 1988;42:534-41.

19 Connor JM, Loughlin SA. Molecular genetics of Turner's syndrome. Acta Paediatr Scand Suppl 1989;356:77-80.

20 Jacobs PA, Betts PR, Cockwell AE, Crolla JA, Mackenzie MJ, Robinson DO, et al. A cytogenetic and molecular reappraisal of a series of patients with Turner's syndrome. Ann Hum Genet 1990;54:209-23.

21 Villamar M, Fernandez E, Ayuso C, Ramos C, Benitez J. Study of the parental origin of sexual aneuploidy in ten families using RFLPs. Ann Genet 1990;33:29-31.

22 Loughlin SA, Redha A, McIver J, Boyd E, Carothers A, Connor JM. Analysis of the origin of Turner's syndrome using polymorphic DNA probes. $\mathcal{F}$ Med Genet 1991;28:156-8.

23 Lorda-Sanchez I, Binkert F, Maechler M, Schinzel A. Molecular study of 45,X conceptuses: correlation with clinical findings. Am $₹$ Med Genet 1992;42. 487-90.

24 Larsen T, Gravholt CH, Tillebeck A, Larsen H, Jensen MB, Nielsen J, et al. Parental origin of the $\mathrm{X}$ chromosome, $\mathrm{X}$ chromosome mosaicism and screening for "hidden" $Y$ chromsome in 45, $X$ Turner syndrome ascertained cytogenetically. Clin Genet 1995;48:6-11.

25 Gravholt $\mathrm{CH}$, Friedrich U, Nielsen J. Chromosomal mosaicism: a follow-up study of 39 unselected children found at birth. Hum Genet 1991;88:49-52.

26 Kulkarni R, Hawkins J, Bradford WP. Prenatal diagnosis of 45,X/46,XX mosaicism in the fetus. Should the pregnancy be terminated? Prenat Diag 1989;9:439-41.

27 Roland B, Cox DM, Rudd NL. Sex chromosome mosaicism not detected at amniocentesis. Prenat Diagn 1990;10:333-6.

28 Schwinger E, Seidl E, Klink F, Rehder H. Chromosome mosaicism of the placenta-a cause of developmental failure of the fetus? Prenat Diagn placenta-a caa

29 Tharapel AT, Elias S, Shulman LP, Seely L, Emerson DS, Simpson JL Resorbed co-twin as an explanation for discrepant chorionic villus results: non-mosaic $47, \mathrm{XX},+16$ in villi (direct and culture) with normal $(46, \mathrm{XX})$ amniotic fluid and neonatal blood. Prenat Diagn 1989;9:467-72.

30 Nisani R, Chemke J, Voss R, Appelman Z, Caspi B, Lewin A, et al. The dilemma of chromosomal mosaicism in chorionic villus sampling - 'direct' versus long-term cultures. Prenat Diagn 1989;9:223-6.

31 Tomkins DJ, Vekemans MJ. False-positive and false-negative cytogenetic findings on chorionic villus sampling letter. Prenat Diagn 1989;9:139-40.

32 Miny P, Hammer P, Gerlach B, Tercanli S, Horst J, Holzgreve W, et al. Mosaicism and accuracy of prenatal cytogenetic diagnoses after chorionic villus sampling and placental biopsies. Prenat Diagn 1991;11:581-9.

(Accepted 17 October 1995)

\section{ONE HUNDRED YEARS AGO}

\section{THE EMBARRASSMENT OF GUY'S HOSPITAL.}

The authorities of Guy's Hospital are now making a determined attempt to raise a sum of $£ 500,000$ for investment, to make good the depreciation in income from the endowments, which almost wholly consist of agricultural property. That an appeal from a great institution like Guy's is a matter of national importance is evidenced by the warm interest which the Prince of Wales is taking in the movement for re-endowment, and H.R.H. will preside on May 20th next at the only festival dinner ever held in connection with this hospital. A feature of the movement of much interest, more especially to the medical profession, is the manner in which old Guy's men and present students are rallying to the support of their Alma Mater. Already Guy's men in practice have influenced several munificent donations, while it is believed that the majority are doing something. The present members of the Medical School have voluntarily organised themselves into a collecting committee, and, if Providence helps those who help themselves, then it may safely be prophesied that Guys Hospital will not only maintain its present position, but also reopen its closed beds. (BMF 1896;i:682.) 